\title{
CONSTRUÇÃO DA IDENTIDADE DOCENTE DE UM ESTUDANTE DE LICENCIATURA EM CIÊNCIAS BIOLÓGICAS EM CURSO A DISTÂNCIA: UM CASO DE HIBRIDISMO
}

\begin{abstract}
RESUMO: Partindo da compreensão da formação da identidade docente como entrelaçada às interações sociais nos diversos contextos, ampliamos esse pressuposto, articulando-o à abordagem da produção da identidade cultural, que ressalta sua relação constitutiva com a linguagem. A partir desse percurso, compomos um quadro teórico incorporando conceitos da filosofia da linguagem. Buscamos investigar, por meio de entrevista, a construção discursiva da identidade docente de um estudante do último período de um curso a distância de licenciatura em Ciências Biológicas, utilizando um dispositivo analítico Bakhtiniano. Concluímos que a construção discursiva da identidade docente do estudante caracteriza-se por hibridismo, o que pode estar relacionado, principalmente, ao seu apego à identidade profissional de extensionista rural manifestado de várias formas ao longo da entrevista.
\end{abstract}

Palavras-chave: Identidade docente. Licenciatura em Ciências Biológicas. Educação a distância. Hibridismo.

THE CONSTRUCTION OF THE TEACHING IDENTITY OF A STUDENT FROM A BIOLOGY PRE-SERVICE TEACHING DISTANCE COURSE: A CASE OF HYBRIDISM ABSTRACT: Starting from the understanding of the formation of the teaching identity as interlaced with social interactions in different contexts, we have extended such an assumption, coordinating it to the production of cultural identity approach, which emphasizes its constitutive relationship with language. From this path, we composed a theoretical framework incorporating concepts of philosophy of language. We seek to investigate, through interviews, the discursive construction of the teaching identity of a student from the last period of a distance course degree in Biological Sciences. This was carried out by using a Bakhtinian analytical device. We conclude that the discursive construction of teaching identity of the student analyzed is characterized by hybridism, which may be related primarily to his attachment to the professional identity of rural extension educator manifested in various ways throughout the interview.

Keywords: Teaching identity. Biological Sciences. Degree. Distance Education. Hybridism.

\section{Mara Lúcia Rodrigues Costa* \\ Flavia Rezende**}
*Doutoranda do Programa de Pós- graduação NUTES-UFRJ E-mail: mlrcosta@uol.com.br
* *Doutora em Educação pela Pontifícia Universidade Católica do Rio de janeiro (PUC-Rio)
Professora associada III do Núcleo de Tecnologia Educacional para a Saúde da Universidade Federal do Rio de Janeiro (NUTES-UFRJ). E-mail: flaviarezende@uol.com.br




\section{PROBLEMATIZAÇÃO}

A expansão da Educação a Distância (EaD) no Brasil está relacionada a fatores como a globalização da economia e a necessidade de proporcionar qualificação para um mercado de trabalho cada vez mais exigente (SILVA Jr., 2003), as reformas educacionais propostas por organismos internacionais como o Banco Mundial e a Organização para Cooperação e Desenvolvimento Econômico e a carência de professores.

Desde a década de 1990, o governo tem investido em infraestrutura administrativa e em programas como a TV Escola e o Programa Nacional de Informática na Educação, no sentido de ampliar a incorporação das tecnologias digitais da informação e comunicação (TDIC) na Educação e permitir o avanço da EaD. Com essas iniciativas, a EaD passa a figurar como integrante do sistema formal de ensino, sendo referendada pela Lei de Diretrizes e Bases da Educação Nacional (BRASIL, 1996) como uma das modalidades de oferta de Educação do sistema educacional, regulamentada pelo Decreto $n^{\circ} 5.622 / 2005$ e Portaria Ministerial $n^{\circ}$ 4.361/2004. Como resultado dessa lógica expansionista (SEGENREICH, 2009) adotada pelo governo nesse período, várias universidades (preponderantemente públicas) começam a oferecer cursos de graduação a distância voltados principalmente para a certificação de professores de Ensino Fundamental.

Nesse contexto, foi criado, em 2006, o Sistema Universidade Aberta do Brasil (UAB), visando ao "desenvolvimento da modalidade de educação a distância, com a finalidade de expandir e interiorizar a oferta de cursos e programas de educação superior no País” (BRASIL, 2006). Trata-se de um sistema integrado por universidades públicas que oferece cursos de nível superior para camadas da população que têm dificuldade de acesso à formação universitária, por meio do uso da metodologia da EaD. O atendimento é prestado ao público em geral, mas a prioridade é dada à formação de professores já atuantes na educação básica, seguidos dos dirigentes, gestores e trabalhadores em educação básica dos estados, municípios e do Distrito Federal.

De acordo com Giolo (2008), o processo de expansão da EaD, desencadeado pela LDB de 1996, inicialmente conduzido pelas instituições públicas, passa, a partir de 2002, a ter a participação do setor privado, que em pouco tempo lhe confere um papel bem distinto daquele de complementar a educação presencial, como suposto pela legislação. A EaD torna-se objeto de disputa do mercado educacional, voltando-se prioritariamente para os cursos de graduação de fácil oferta, como verificado na área de Educação, por exemplo, em que o aumento percentual da $\mathrm{EaD}^{1}$ foi muito maior que em outras áreas.

Nas licenciaturas, enquanto o percentual de crescimento das matrículas nos cursos presenciais experimentava um decréscimo, nos cursos a distância teve aumento de 90,6\%. Essa tendência de substituição da formação docente presencial pela formação a distância vem se mantendo, já que em 2010 (BRASIL, 2011) $45,8 \%$ das matrículas em licenciatura foram feitas na modalidade a distância, en- 
quanto a escolha pela modalidade presencial representou somente 17,0\% das matrículas. Em 2011, (BRASIL, 2013) verificou-se decréscimo de 0,2\% nas matrículas em cursos presenciais de licenciatura e um aumento de $0,8 \%$ nas matrículas em cursos de licenciatura a distância, mantendo-se, assim, a mesma tendência verificada no ano anterior.

A EaD se constitui como um conjunto de práticas que se materializam na reconfiguração do ensino e do trabalho docente, em que as funções tradicionalmente atribuídas ao professor, como mediação do conhecimento, gestão de interações em sala de aula e avaliação passam a ser mediadas por comunicação secundária, viabilizada pelas TDIC, exercidas por diferentes pessoas e de forma externa à sala de aula. Autores como Zuin (2006) e Giolo (2008) problematizam essa virtualização do processo de ensino e aprendizagem, supondo que ela possa levar à privação das relações intersubjetivas entre professor e estudante. Giolo (idem) lembra que no ensino presencial, o conjunto de atividades desempenhadas pelo professor, o ambiente em que os fatos acontecem e a natureza das relações que são construídas são elementos constitutivos do processo formativo, portanto, são decisivos para a formação docente. $\mathrm{O}$ autor chama nossa atenção para o conjunto de espaços de socialização que estão imersos na instituição educativa, onde as pessoas vivenciam uma cultura específica, experimentando-se "no que sabem e no que podem vir a saber, no que são e no que podem vir a ser” (p. 1228), ou seja, na formação de sua identidade e de sua identidade docente. Para Zuin (idem), a comunicação virtualizada se concretiza em um fetiche de que esse tipo de comunicação tornou-se hegemônica em relação à presencial. $\mathrm{O}$ autor considera que a proximidade possibilitada pelas TDIC não se confunde com a proximidade humana no sentido "da participação mútua e da identificação, que só podem ser gradativamente construídas ao longo do convívio mútuo e da troca de experiências" (TURCKE apud ZUIN, 2006, p. 941).

Sob o lema da suposta superação das distâncias geográficas e das desigualdades sociais, a proposta da formação inicial de professores a distância concorre, segundo Barreto (2004), para um claro processo de massificação da formação docente. Esse sistema de formação tem sido relacionado à democratização e circunscrito à racionalidade instrumental, porém, com destaque para sua viabilidade econômica, ou seja: "o que está em questão é o barateamento desta formação, nos seus diferentes sentidos" (BARRETO, 2008, p. 930). Percebe-se, assim, que a autora também manifesta sua preocupação com a qualidade da formação docente a distância no contexto educacional brasileiro.

Tais aspectos da formação docente a distância, abordados criticamente por esses autores, foram trazidos no sentido de problematizar a expansão desenfreada de cursos de licenciatura a distância e a possível falta de qualidade que pode estar acompanhando esse processo. No entanto, ao alertarmos para as limitações da $\mathrm{EaD}$ não queremos sugerir que essa modalidade educativa resulte sempre em processos formativos aligeirados e sem qualidade, o que é, inclusive, admitido mais recentemente por Zuin (2010) quando considera que "não é possível afirmar, 
categoricamente, que os professores que ministram suas aulas por meio do uso de recursos tecnológicos nunca irão desenvolver tal elo [elo pedagógico], justamente porque se encontram fisicamente afastados de seus alunos” (p. 973).

Já para Silva (2008), o fato de as relações serem virtuais, mediadas pelas TDIC, não significa que haja privação das relações intersubjetivas, mas apenas que essas relações se modificam em alguns aspectos. De acordo com o autor, os botões acionados por cliques no mouse, toques na tela ou combinação de teclas, abrem possibilidades de interatividade em chat, fórum, lista, blog e portfólio. Tais ferramentas podem estar reunidas como convergência de interfaces no ambiente online de aprendizagem para engendrar espaços de cocriação da comunicação e da aprendizagem, capazes de favorecer a expressão do diálogo, do compartilhamento e da autoria colaborativa.

Lapa e Belloni (2012) compreendem que as TDIC oferecem um potencial transformador para a educação, ainda que seja possível ignorar esse potencial e utilizá-las para reproduzir práticas tradicionais, típicas de uma concepção de educação como transmissão de conhecimentos e fazer da EaD uma educação "bancária”. Para mudar esse cenário, é preciso, segundo as autoras, que as TDIC sejam integradas ao processo de aprendizagem, visando a uma formação crítica, tanto em sua capacidade reflexiva como nas formas de ação política. Para isso, é necessário passar da lógica da transmissão para a lógica da interatividade, criando condições de usos horizontais, propiciando uma comunicação bidirecional e em rede que favoreça a participação ativa dos estudantes. De qualquer modo, as autoras esclarecem que são as opções pedagógicas que determinarão a qualidade da educação, sendo a tecnologia apenas um vetor da mudança.

As perspectivas sobre a EaD e, especificamente, sobre a formação docente a distância aqui levantadas, tangenciam, a partir de argumentos diferentes, a questão da construção da identidade do professor. Giolo (2008) enfatiza a impossibilidade de se desconsiderar o lócus formativo (presencial) e a cultura específica na construção dessa identidade, enquanto Zuin (2006) aponta a necessária proximidade entre os sujeitos para que, por meio da troca de experiências e do convívio (presencial), sejam vivenciados processos de identificação. Barreto (2008) se refere ao empobrecimento da formação docente nos processos a distância. Já Silva (2008) e Lapa e Belloni (2012) defendem os processos formativos a distância, chamando atenção para o papel da tecnologia como propiciadora de mudanças que podem afetar positivamente a qualidade da formação e, consequentemente, da identidade docente.

O presente estudo tem como objetivo analisar a construção da identidade docente em um curso a distância de licenciatura em Ciências Biológicas oferecido por uma universidade privada ${ }^{2}$, inserindo-se, portanto, no contexto atual de expansão (e privatização) da oferta de cursos de licenciatura a distância vivido no país. Para dar conta de nosso objetivo, partimos da problematização apresentada anteriormente e elegemos o pensamento de Nóvoa (2007) como a origem de um recorte teórico. Para esse autor, a construção da identidade profissional do professor é 
um processo de construção social, complexo e dinâmico, que necessita de tempo para assimilar mudanças e perspectivas que vão caracterizar a maneira como cada um se sente e se diz professor. Esse processo é constituído de posturas produzidas individual e coletivamente, nas interações sociais. Como resultado dessas interações, tem-se uma série de representações que os docentes fazem de si mesmos, as quais são fruto do diálogo entre os mundos objetivo e subjetivo do indivíduo, de suas condições cotidianas de trabalho, do imaginário acerca da profissão de professor e dos discursos que circulam no mundo social e cultural da escola e dos docentes.

Assim, entendendo que a formação da identidade docente está entrelaçada aos processos de socialização e às interações sociais nos diversos contextos nos quais o sujeito está inserido, propomos a ampliação desse pressuposto, articulando-o à abordagem teórica da produção da identidade cultural (HALL, 2011; SILVA, 2011), que ressalta, nesse processo, sua relação constitutiva com a linguagem. A partir desse percurso, compomos um quadro teórico incorporando conceitos da filosofia da linguagem (BAKHTIN, 1981; 1995; 1997) que contribuirão para a operacionalização de um dispositivo analítico.

\section{CONSTRUC̣ÃO DISCURSIVA DA IDENTIDADE}

De acordo com Hall (2011), as identidades são construídas nas narrativas pessoais e é justamente por serem construídas dentro e não fora do discurso que necessitam ser compreendidas como produzidas em espaços "históricos e institucionais específicos, no interior de formações e práticas discursivas específicas, por estratégias e iniciativas específicas" (p. 109). O autor salienta, ainda, que as identidades emergem em meio aos jogos de poder, e por isso mesmo são marcadas pela diferença e pela exclusão muito mais do que por uma unidade idêntica, como no seu significado tradicional.

Assim, a construção da identidade é um processo forjado na diferença ou por meio dela e reelaborado pelos processos de exclusão/diferenciação. Para Silva (2011), identidade e diferença possuem uma relação de estreita dependência, são inseparáveis e partilham uma característica importante: ambas são fruto de atos de criação linguística e, portanto, são produzidas pelo universo cultural e social. Por serem atos linguísticos, a identidade e a diferença estão sujeitas a determinadas características da linguagem em geral. Dessa forma, elas não podem ser analisadas destacadas dos sistemas de significação nos quais ganham sentido e são, assim, governadas pela estrutura da linguagem. No entanto, Silva (op. cit.) afirma que essa estrutura é caracterizada pela indeterminação e pela instabilidade, o que torna a identidade e a diferença igualmente indeterminadas e instáveis.

Uma vez que nos definimos levando em conta o outro e a coletividade por meio da palavra, é justamente nela que podemos perceber as construções identitárias. A partir dessa relação constitutiva da identidade com a linguagem, aproximamos o processo de formação da identidade - e da identidade docente 
- à formação discursiva do sujeito, completando o quadro teórico com conceitos da filosofia da linguagem. Bakhtin (1995) e seu círculo colocam o sujeito como um agente constituído sócio-historicamente que não pode ser o resultado de um determinismo mecânico da estrutura, tampouco fruto de uma individualidade autoconsciente e livre de coerções. Para o autor, a consciência é impregnada de conteúdo ideológico no processo de interação social, por meio da interação verbal.

As formas de interação verbal estão, assim, fortemente atreladas a um dado contexto social, reagem a todas as flutuações da atmosfera social e se realizam por meio de enunciados. O enunciado reflete as condições específicas e as finalidades da atividade humana e da utilização da língua "não só por seu conteúdo (temático) e por seu estilo verbal, ou seja, pela seleção operada nos recursos da língua - recursos lexicais, fraseológicos e gramaticais -, mas também, e, sobretudo, por sua construção composicional” (BAKHTIN, 1997, p. 279). Os três elementos estão integrados de forma indissociável no "todo" do enunciado, criando marcas específicas de uma dada esfera da comunicação e elaborando tipos relativamente estáveis de enunciados.

O conceito de dialogia (BAKHTIN, 1981), compreendido como a condição interdiscursiva da linguagem, pode ser aproximado da construção discursiva da identidade, uma vez que está relacionado ao diálogo permanente com o outro. Nesse sentido, os enunciados podem ser vistos como diálogos nos quais são travados embates ideológicos e confrontadas visões de mundo. Segundo Freitas (2010), a noção de dialogia afina-se com a concepção de identidade cultural de Hall (2011), pois os sujeitos participam do "simpósio universal" que rege o funcionamento da língua, tornando possível que a identidade seja produzida na enunciação, uma vez que ela não está definida a priori, mas é sempre declarada a partir da diferença, em uma situação dialógica.

A produção discursiva - e dialógica - da identidade busca por fixação, mas assim como acontece com a linguagem, tende a escapar, passando por processos que a complicam e subvertem. Tais processos são caracterizados, segundo Silva (2011), pela mistura, combinação ou diálogo entre diferentes grupos, gerando uma identidade "que não é mais integralmente nenhuma das identidades originais, embora guarde traços delas” (p. 87). O conceito de hibridismo (BAKHTIN, 1981) tem sido usado por autores dos estudos culturais para compreender a construção identitária. Por esse conceito, Bakhtin (idem) designa um enunciado de acento duplo e estilo duplo que pertence a um só falante, mas que de fato "contém misturados dentro dele dois enunciados, duas formas de fala, dois estilos, 'duas linguagens', dois sistemas semânticos e axiológicos” (p. 304, tradução nossa).

A partir desse quadro teórico, buscamos investigar a construção discursiva da identidade docente de um licenciando do último semestre de um curso a distância de licenciatura em Ciências Biológicas, procurando indícios de relações dialógicas com discursos associados ao contexto formativo ou a outros contextos sociais. 


\section{PROCEDIMENTOS METODOLÓGICOS}

Com o intuito de investigar a construção discursiva da identidade docente no curso mencionado, foi realizada uma entrevista semiestruturada com quatro estudantes que estavam cursando o último semestre e que não tinham cursado outra graduação anteriormente. Com esses critérios, pretendíamos localizar enunciados que dialogassem com discursos relacionados àquele curso. Para tal, foi elaborado um protocolo de entrevista composto por dez perguntas sobre aspectos da formação docente vivenciados no curso e um questionário relativo às características socioeconômicas e culturais dos estudantes. Para este trabalho, selecionamos a entrevista que apresentava respostas mais desenvolvidas e que, por isso, poderiam oferecer mais elementos para análise da construção discursiva de uma identidade docente.

Embora não pretendamos generalizar os resultados deste estudo, consideramos que seja possível encontrar, nessa entrevista, enunciados comuns aos de outros estudantes do curso, tendo em vista que eles compartilhavam o mesmo contexto enunciativo. Nessas circunstâncias, supomos poder haver, conforme sugerem os estudos de caso (MERRIAN, citado por ANDRÉ, 2005), aproximações entre os processos de construção da identidade docente.

Tomando as respostas do estudante como enunciados, utilizamos um dispositivo analítico (VENEU, 2012; FERRAZ, 2012) elaborado a partir da metodologia de estudo da língua proposta por Bakhtin (1995). O dispositivo compreende os seguintes procedimentos: (1) Identificação do enunciado: a alternância entre os sujeitos falantes é suficiente para identificar o enunciado, iniciando-se no momento em que o falante toma a palavra para si e finalizando-se no momento em que este termina o que gostaria de dizer; (2) Leitura preliminar do enunciado: o objetivo dessa etapa é o primeiro contato com os enunciados no sentido de identificar preliminarmente seus elementos linguísticos (itens lexicais, estilo, construção composicional, unidade temática, conclusibilidade e relação com o falante e outros participantes) e fazer uma articulação prévia entre o material linguístico, o objetivo da pesquisa e os conceitos bakhtinianos; (3) Descrição do contexto extraverbal: os elementos do contexto extraverbal são descritos e articulados com vistas a estabelecer o horizonte espacial comum dos interlocutores, a avaliação comum da situação, o momento social e histórico em que eles ocorrem e a rede de enunciados a que se relacionam e são complementados com elementos do contexto extraverbal individual; (4) Análise do enunciado: consiste em articular os elementos linguísticos, o contexto extraverbal e os conceitos bakhtinianos envolvidos para alcançar o objetivo da pesquisa.

\section{RESULTADOS DA ANÁLISE}

Apresentamos a análise da entrevista, buscando, na articulação das etapas do dispositivo analítico, elementos discursivos e relações dialógicas envolvidas na construção da identidade docente do estudante. 


\section{Identificação dos enunciados}

Sendo os enunciados produzidos a partir de perguntas da entrevistadora, a alternância dos sujeitos falantes é bem clara: a pesquisadora faz a pergunta e o estudante responde. Assim, cada resposta do estudante é considerada um enunciado.

\section{Leitura preliminar dos enunciados do estudante}

A primeira característica que chamou atenção diz respeito às dúvidas recorrentes quando o estudante expressa suas perspectivas. Outro traço das enunciações do estudante é a transformação de experiências pessoais em generalizações. Quando constrói justificativas a respeito de suas escolhas, ele se pauta na sua experiência de vida. Também notamos que as respostas às perguntas 4, 5 e 6 são bem mais curtas que as demais.

\section{Contexto extraverbal}

O momento social e histórico em que ocorre a interação verbal com o estudante é marcado pela expansão da EaD, principalmente como modalidade de formação de professores por instituições de ensino superior. $O$ entrevistado pertence a uma turma de 24 licenciandos do último semestre do curso a distância de licenciatura em Ciências Biológicas. O curso é desenvolvido em três anos e abrange, concomitantemente, um componente curricular, de conteúdos específicos, e outro de conteúdos pedagógicos. Ambos são desenvolvidos por meio de disciplinas a distância complementadas por encontros presenciais e contam com um professor-tutor e com atividades de estudo disponíveis em um ambiente virtual.

O componente curricular de conteúdos específicos é composto por 27 disciplinas cobrindo todas as áreas das ciências biológicas. O componente curricular pedagógico compreende uma disciplina de Prática de Ensino por semestre, Estágios Supervisionados I e II, além das disciplinas: Escola e Sociedade I e II; Espaço Pedagógico da Sala de Aula I e II; Ensino-Aprendizagem de Ciências Biológicas I e II.

Até o terceiro semestre, os estudantes recebiam os roteiros de estudo impressos e em Cds nos quais constavam os conteúdos e as atividades referentes à cada semestre. Os encontros presenciais ocorriam mensalmente, em um final de semana, alternando entre um mais longo, com duração de 16 horas e ministrado por professores especialistas, e outro mais curto, com duração de 08 horas, administrado por um preceptor. Esses encontros presenciais correspondem a 30\% da carga horária total do curso, que é de 2960 horas. A comunicação professor-aluno entre esses encontros era feita por telefone ou e-mail.

A partir do terceiro semestre, o curso passou a contar com um ambiente virtual de aprendizagem no qual os estudantes tinham acesso às atividades que precisavam desenvolver em cada semestre, a serem corrigidas pelos professores-especialistas; além disso, podiam participar de fóruns de discussão, acessar o calendário e a agenda do curso, a biblioteca virtual, visualizar suas notas e enviar mensagens aos professores, ao professor-tutor e ao preceptor para esclarecimento de dúvidas. Em função dessas alterações, surge a figura do professor-tutor, nesse 
caso, uma das autoras deste trabalho, responsável por ministrar aulas de revisão do conteúdo nos encontros presenciais e corrigir algumas das atividades disponíveis no ambiente virtual.

A entrevista, realizada por uma das autoras, ocorreu no último encontro presencial do curso, entre as atividades programadas. O estudante sabia que dentro do planejamento proposto para esse encontro haveria um momento com a professora-tutora e outro com a preceptora. Também estava ciente de que, ao final, os estudantes seriam entrevistados pela professora-tutora. O entrevistado estava ciente de que a professora-tutora era estudante de doutorado em uma instituição pública federal, no Rio de Janeiro. Portanto, conhecia o seu interlocutor e já tinha uma relação estabelecida com ele. Também estava ciente de que o objetivo da entrevista era investigar a formação da identidade docente de sujeitos que tiveram sua formação inicial na modalidade a distância e que a entrevista tinha como objetivo identificar aspectos dessa formação. Isso seria feito por meio da análise das respostas à entrevista que iria se seguir. Por estar em contato com o ambiente universitário, supomos que o entrevistado considera a qualificação acadêmica importante tanto para o processo de ensino e aprendizagem como para obtenção de certificados e valorização profissional.

A partir do questionário sociocultural foi possível obter a informação de que o estudante entrevistado tem 33 anos, possui o curso técnico de Agropecuária, o curso técnico pós-médio em Meio Ambiente e trabalha como extensionista rural ${ }^{3}$ na Empresa de Assistência Técnica e Extensão Rural do Estado de Minas Gerais.

Sua renda familiar vai de um a três salários mínimos. Sempre estudou e trabalhou. Sua carga horária de trabalho é de quarenta horas semanais. É o principal responsável pela renda familiar. Cursou o ensino básico em escola pública, sendo que o Ensino Médio foi feito concomitantemente com um curso técnico. Após concluí-lo, houve uma interrupção dos estudos. Seu pai tem formação superior incompleta e sua mãe tem o Ensino Fundamental incompleto.

\section{Análise dos enunciados}

Nesta seção, apresentamos cada pergunta da entrevista seguida do enunciado (resposta) do estudante e da respectiva análise.

Pergunta 1: O que fez você optar pelo ensino a distância?

\begin{tabular}{|c|l|}
\hline 1 & Primeiro foi a facilidade. Conciliando aqui, assim, o ensino a distância não dificultou \\
\hline 2 & o exercício da minha profissão. Mesmo tendo um horário fixo o desempenho de \\
\hline 3 & algumas atividades acaba tendo, provocando, uma certa flexibilidade do horário de \\
\hline 4 & trabalhar até à noite, às vezes. Primeiro, eu acredito, pensando que poderia ter essa \\
\hline 5 & flexibilidade fazendo meu próprio turno de estudo. Em segundo lugar, talvez pela \\
\hline 6 & modalidade de ensino que vem de encontro do que tava mais com afinidade, a \\
\hline 7 & profissão que eu exerço também. \\
\hline
\end{tabular}


O estudante justifica a opção pela EaD alegando que essa modalidade não era um empecilho para o exercício de sua atual profissão. Utiliza o substantivo "facilidade" e o verbo “conciliar"(linha 1) para explicar as vantagens proporcionadas pela EaD. Utiliza também o substantivo "flexibilidade" e o verbo "acreditar" para se referir à adequação dos horários de trabalho com o estudo para reforçar sua crença de que a EaD seria vantajosa para ele. Quando expõe sua segunda explicação, utiliza o advérbio "talvez" (linha 5) para expressar como justificativa, a "afinidade" (linha 6) entre seu conteúdo e o de sua atual profissão.

Pergunta 2: Qual o motivo de optar pelo curso de licenciatura em Ciências Biológicas?

\begin{tabular}{|c|l|}
\hline 1 & Até conforme eu estava falando antes, realmente, assim, é, eu estava mais próximo da \\
\hline 2 & minha atividade. Se eu fosse falar assim, justificar os motivos. A minha formação \\
\hline 3 & Acadêmica, como é na área de ensino técnico em Ciências Agrárias, cheguei até fazer \\
\hline 4 & curso de Meio Ambiente. Isso tudo foi inclinando, porque meu desejo, no início, era tá \\
\hline 5 & cursando, talvez, um curso de Zootecnia ou Agronomia. Pensei em Medicina \\
\hline 6 & Veterinária. E por já tá num emprego fixo e não ter, talvez, a possibilidade de tá fazendo \\
\hline 7 & um curso desse, não existe essa modalidade, Ciências Agrárias a distância. Eu optei \\
\hline 8 & por Biológicas, pelo fato de ter essa proximidade, tá relacionado e com isso eu tô me \\
\hline 9 & apropriando de conhecimentos que tão melhorando ainda mais meu desempenho \\
\hline 10 & profissional. \\
\hline
\end{tabular}

O estudante se remete ao final do enunciado anterior, utilizando o advérbio de tempo "antes" (linha 1), indicando continuidade. Ele justifica a opção pelo curso fazendo referência à sua atividade profissional (linha 2) e logo em seguida faz alusão à sua formação técnica em Ciências Agrárias e em Meio Ambiente (linhas 2, 3 e 4), utilizando o verbo "inclinar" (linha 4) para justificar uma certa aproximação. Percebe-se que sua opção não está diretamente ligada à docência da Biologia, mas à possível convergência do conteúdo do curso com sua ocupação técnica.

$\mathrm{Na}$ sequência de sua fala, ele expressa que o seu real interesse era fazer um curso superior na área de Ciências Agrárias, apesar de não expressar certeza, já que usa o advérbio de dúvida "talvez" (linha 5). E acaba justificando sua opção pelo curso a distância de licenciatura em Ciências Biológicas devido ao fato de ter um emprego fixo e à inexistência de cursos a distância na área de Ciências Agrárias.

$\mathrm{Na}$ parte final do enunciado, reforça ter feito a opção pelo curso "pelo fato de ter essa proximidade" (linha 8). O uso do pronome "essa" indica o que já foi dito no discurso e a palavra "proximidade" indica vizinhança que, no caso, está se referindo à relação do curso de Ciências Biológicas à área das Ciências Agrárias, já apontada antes. Em seguida, utiliza o pronome "isso" novamente, fazendo referência ao que já havia dito, no caso, ter feito opção pelo curso de licenciatura em Ciências Biológicas, e deixa transparecer que tal escolha está sendo vantajosa para o seu desempenho profissional, quando usa o verbo “melhorar"(linha 9). 
Pergunta 3: Quando optou pelo ensino a distância, o que sabia sobre essa modalidade de ensino?

\begin{tabular}{|c|l|}
\hline 1 & Olha, sabia que era uma modalidade que exigia um certo nível de comprometimento dos \\
\hline 2 & estudantes, apesar da facilidade de você tá todo dia em casa. Mas eu olhei também esse \\
\hline 3 & Aspecto, tá dentro do conforto do meu lar, de minha casa e até tá podendo, também, \\
\hline 4 & conciliar com estudos. Esse item foi até mais exigente do que eu tava esperando, mas \\
\hline 5 & consegui, tô conseguindo, assim, ampliar minhas habilidades. E eu conhecer esse lado \\
\hline 6 & meu como educador, apesar de trabalhar na área como extensionista rural, tem a sua \\
\hline 7 & didática. Existe certo dinamismo na instrução de várias pessoas, de várias faixas \\
\hline 8 & etárias, várias faixas econômicas, e diferentes situações. O curso de licenciatura me \\
\hline 9 & ampliou, me deu essa possibilidade de tá enxergando isso por um outro ponto. \\
\hline
\end{tabular}

Novamente o estudante se refere à possibilidade de conciliar trabalho e estudo (linhas 1 e 2). Quando menciona o "comprometimento" (linha 1), a palavra vem modulada com o adjetivo "certo" (linha 1), o que indica que não foi visto por ele como um comprometimento importante. $\mathrm{Na}$ linha 4 ele inicia a frase dizendo "Esse item foi até mais exigente do que eu tava esperando". O uso do pronome "esse" indica que ele está se referindo aos estudos, que esperava que fossem menos exigentes. Pode estar embutida, até aqui, uma concepção de EaD como uma alternativa educacional mais fácil do que a presencial. Ainda nessa construção, utiliza a conjunção adversativa "mas"(linha 4), indicando que está conseguindo ampliar suas habilidades, mesmo não sendo fácil como esperava. É possível observar que as habilidades a que ele está se referindo são as de extensionista rural, que teriam uma interface com a docência, como se percebe na alusão ao termo "didática" (linha 7), típico do campo da educação. Assim, novamente faz alusão à sua profissão, apontando que está se beneficiando das habilidades pedagógicas que adquiriu no curso para lidar, enquanto extensionista rural, com um público diversificado e em situações distintas. Menciona que adquiriu essas habilidades no curso de licenciatura, associando-as à situação de estar "enxergando isso por um outro ponto" (linha 9), apesar de não explicitar qual seria esse ponto.

Pergunta 4: Como você avalia o uso das tecnologias da informação e comunicação (TIC) no curso?

\begin{tabular}{|c|l|}
\hline 1 & Agilizam o processo de ensino, ou seja, reduz a distância ou até eliminam a distância \\
\hline 2 & entre elementos constituintes do processo de ensino. \\
\hline
\end{tabular}

O estudante utiliza o verbo "agilizar" (linha 1) para se referir a uma característica do processo de ensino virtual vivenciado no curso. $\mathrm{Na}$ sequência, utiliza a expressão explicativa "ou seja” (linha 1) dando a entender que irá dizer o mesmo com outras palavras. Entretanto, ele passa a se remeter ao aspecto espacial, citando a 
diminuição ou eliminação da distância entre os elementos constituintes do processo de ensino. Também notamos, pelo uso do presente do indicativo, a produção de um enunciado atemporal, que se compromete pouco com o contexto específico do curso.

Pergunta 5: Como você avalia sua interação por meio das TIC com os professores, preceptor e os seus colegas?

\begin{tabular}{|l|l|}
\hline 1 & Poderia ter sido mais intensa, pois sustentei minha participação somente naquilo que \\
\hline 2 & fui induzido a participar. \\
\hline
\end{tabular}

O estudante usa o futuro do pretérito para indicar que as interações mediadas pelas TIC com os outros sujeitos não foram intensas como poderiam ser. Complementa a sua fala explicando que sua interação foi restrita "somente" (linha 1) àquilo que foi levado a participar. Ele parece assumir que a interação virtual foi reduzida devido à sua própria decisão de participar dela exclusivamente para realizar o que era solicitado no curso.

Pergunta 6: Como você avalia sua formação docente na modalidade a distância tendo como referência o ensino presencial?

\begin{tabular}{|l|l|}
\hline 1 & Boa, pois os momentos dedicados ao estágio permitiram o contato com a realidade, \\
\hline 2 & porém, entendendo que a habilidade em ser docente é algo que é feito constantemente. \\
\hline
\end{tabular}

O estudante avalia positivamente a formação docente recebida, utilizando o adjetivo "boa" e se referindo unicamente ao estágio. Justifica sua avaliação assinalando o quanto o estágio permitiu "o contato com a realidade". Contudo, utiliza a conjunção "porém" (linha 2), fazendo uma restrição ao que foi dito anteriormente, explicitando que em sua concepção, a formação docente não se restringiria apenas àqueles momentos, ocorrendo "constantemente" (linha 2).

Pergunta 7: Como você avalia a formação recebida no curso, ou o processo formativo pelo qual passou diante do desafio de lecionar Ciências e Biologia?

\begin{tabular}{|c|l|}
\hline 1 & Até brinco, já brinquei, né? Eu acho que o curso só vai começar só quando a gente \\
\hline 2 & termina. Não sei se é porque eu sou fruto de um Ensino Médio e técnico que eu \\
\hline 3 & conciliava. Quando eu formei já tava no curso profissionalizante, eu percebi que \\
\hline 4 & achando que já sabia alguma coisa, mas fui me deparar só quando iniciei o meu \\
\hline 5 & trabalho, né? Que realmente exercendo a profissão é que eu estava começando a \\
\hline 6 & aprender. Então, assim, a escola, ela mostra os caminhos, mas quem faz a escola é o \\
\hline 7 & aluno. Então eu tô me sentindo nessa posição. Ela me mostrou o básico, ela vem \\
\hline 8 & mostrando o básico. Não sei se é da minha pessoa, ou dentro da, dessa concepção de \\
\hline 9 & ensino que eu recebi dentro da universidade, a formação não acaba com a formatura. \\
\hline
\end{tabular}




\begin{tabular}{|l|l|}
\hline 10 & A formação, o próprio nome fala, formar em ação, você tá sempre em ação, se \\
\hline 11 & autoformando de acordo com as concepções, os conceitos, por que isso tudo é \\
\hline 12 & permanente a mudança disso. Então, nessa parte eu vejo assim, que eu nunca vou \\
\hline 13 & parar de aprender. Eu falo que só depois que eu formar realmente que eu vou tá \\
\hline 14 & começando o verdadeiro curso e exercer com plenitude, mas independente disso ou \\
\hline 15 & não, o conteúdo que eu me aproprio hoje tem significância sim, no que eu estou. \\
\hline
\end{tabular}

O estudante explicita sua concepção a respeito do processo formativo: "O curso só vai começar só quando agente termina” (linhas 1 e 2). Para justificar essa ideia, expressa, ainda, com dúvida ("não sei", linha 2), sua perspectiva, e dialoga com sua experiência anterior no Ensino Médio (linhas 2, 3, 4, 5 e 6). Ele reconhece o aprendizado que a escola (e a faculdade) proporcionaram ("Ela me mostrou o básico, ela vem me mostrando o básico", linha 7), entretanto, deixa explícito que é do aluno a responsabilidade pelo processo de aprendizagem (linhas 6 e 7). Ele esboça dúvida a respeito da origem dessa concepção, sem saber distinguir se ela vem de sua experiência de vida ou do que vivenciou no curso (linhas 8 e 9). E para ilustrar seu ponto de vista, inventa uma justificativa etimológica, explicando o significado da palavra "formação" como sendo "formar em ação" (linha 10). Defende que o estudante é formado no trabalho, após a sua formação universitária e, com isso, se esquiva de avaliar a formação recebida no curso (linhas 13, 14 e 15). O fato de evitar fazer a avaliação de sua formação pode estar relacionado à sua imagem da pesquisadora (professora-tutora do curso) como a de alguém que não fosse receptiva à crítica.

Pergunta 8: Como você avalia o conteúdo de ciências biológicas que foi oferecido no curso?

\begin{tabular}{|c|l|}
\hline 1 & Como eu já tô no final, posso falar o seguinte, não foi muito aprofundado em alguns \\
\hline 2 & pontos. Mas se eu for tentar me prender ao que eu justifico com essa formação \\
\hline 3 & continuada, que eu tenho ciência que eu preciso ter ela sempre ao longo da minha vida. \\
\hline 4 & A formação continuada do educador ou do profissional em si, é, ela me deu uma base. \\
\hline 5 & Eu tenho certeza, eu percebo, como muitos dos meus colegas, que também é superficial. \\
\hline 6 & Mas, como tenho essa ciência, a minha pessoa, eu me atrevo a falar que eu acredito que \\
\hline 7 & é só o pontapé inicial. Por já ter passado por um curso profissionalizante, foi a mesma \\
\hline 8 & situação, é muito superficial. Eu lido com muitos estagiários. Eu me remeto há quinze \\
\hline 9 & anos atrás na mesma situação, e eles às vezes ficam assustados com o conteúdo que \\
\hline 10 & dominamos e pensando assim, ah gente, tem hora que não consigo, eu não, nunca \\
\hline 11 & consegui mensurar isso, se não tivesse o contato com quem ta lá no ensino técnico \\
\hline 12 & ainda, e às vezes até acadêmico no futuro, talvez podendo relatar. Eu vejo como seu \\
\hline 13 & caso, e da Adriana, o domínio que tem nossa mãe! Caramba! É uma coisa absurda, \\
\hline
\end{tabular}

Revista Ensaio | Belo Horizonte | v.16 | n. 01 | p. 149-169 | jan-abr | 2014 


\begin{tabular}{|l|l|}
\hline 14 & como é que pode? Fala, mais é aquela questão se você tá praticando, exercendo, aquilo \\
\hline 15 & é uma musculatura trabalhando. Então, assim, resumindo, foi superficial sim, isso eu \\
\hline 16 & não nego, mas eu tinha certeza que o mínimo que foi passado, ou que foi visto, nos \\
\hline 17 & transmite essa compreensão, foi fundamental. Aliás, nem fundamental, foi essencial \\
\hline 18 & porque sem isso você não consegue ampliar o seu domínio. \\
\hline
\end{tabular}

O estudante declara que o conteúdo do curso "não foi muito aprofundado em alguns pontos" (linhas 1 e 2), sem esclarecer quais seriam. Em seguida, ao denominar o curso de licenciatura de "formação continuada" (linha 4), descaracteriza a finalidade própria do curso e dilui a identidade deste, dando ao curso um status acessório. De forma objetiva, reafirma categoricamente que o conteúdo de ciências biológicas oferecido no curso foi "superficial" (linha 5), embora o considere apenas como "pontapé inicial" (linha 7). Justifica a sua opinião sobre a superficialidade dos conteúdos vistos no curso, dialogando com sua experiência no "curso profissionalizante" (linha 7). Compara o conteúdo que ele domina como o dos estagiários com quem lida no seu ambiente de trabalho, sendo que o dele é maior. Também faz esse mesmo tipo de comparação com profissionais de maior graduação, sendo que, nesse caso, o domínio do conteúdo do outro é maior. Para exemplificar essa ideia, remete-se à entrevistadora (linha 13), faz uso de interjeições mostrando uma comparação entre o conteúdo que ele domina e o conteúdo dos professores do curso, sendo que o dos professores é muito maior. O estudante expõe sua concepção de que a prática é que forma e não a formação teórica, quando a compara a "uma musculatura trabalhando"(linha 15). Apesar de afirmar e reafirmar que os conteúdos do curso foram oferecidos de forma superficial, ao final ele os considera fundamentais e até essenciais. Essa contradição pode estar relacionada a um processo de autocensura, quando se dá conta de que estava falando para a professora-tutora do curso.

Pergunta 9: Em sua opinião, que aspectos são necessários para formar um professor?

\begin{tabular}{|c|l|}
\hline 1 & Olha, eu vou tentar falar do jeito que eu tento enxergar. Acho que primeiro é valorizar \\
\hline 2 & a pessoa como ser humano, porque educar não é um simples fato de instruir, ou apenas \\
\hline 3 & ampliar, ou aperfeiçoar habilidades do educando. Acho que é muito mais do que isso. \\
\hline 4 & O salário, sim, sou a favor, se olhar por esse ponto econômico, o salário tem que ser \\
\hline 5 & um salário bom, excelente. Por que o educador, ele tem que ser referenciado, como um \\
\hline 6 & elemento importante, não num aspecto que o pai, os pais, terceirizem ao professor, aos \\
\hline 7 & Professores, a formação do filho, não é nesse ponto. Mas a passagem dele na vida do \\
\hline 8 & aluno é que amplia. Eu pelo menos, eu consigo, graças, não sei se foi dentro de casa, \\
\hline 9 & aonde que eu fui adquirindo isso, a realmente enxergar aquele que te ensina. Eu \\
\hline 10 & considero hoje ex-professores meus, como chamo eles, de professores. Falo “esse aí, é \\
\hline
\end{tabular}




\begin{tabular}{|c|c|}
\hline 11 & meu professor até hoje". Encontro com muitos e falo "esse aí é meu professor", pelo \\
\hline 12 & respeito com que eles me ensinaram, não sei se é pelo amor. Esses que me fizeram que \\
\hline 13 & me passaram isso, eu noto que realmente eles, quando ensinam, não usam a mente, usam \\
\hline 14 & o coração. O coração é que é o transmissor, o que intermedia, parece que é aquela \\
\hline 15 & transpiração que tá muitas vezes no domínio do conteúdo. Ah! Interessante falar nisso, \\
\hline 16 & porque no meu trabalho eu uso isso, às vezes, eu não tenho quase que domínio nenhum \\
\hline 17 & do conteúdo, mas parece que a emoção, quando se articula com conteúdo, você vai \\
\hline 18 & extraindo o conteúdo da pessoa, o saber ali constrói, aqui, você vai ganha uma \\
\hline 19 & confiança, vem uma sintonia, sinergia que seria a palavra, aí, é interessante. Então, \\
\hline 20 & assim, pro educador, o que que é importante é ser valorizado. 0 salário sim, tem que ter, \\
\hline 21 & mas ele também tem que gostar do que faz, não é pra qualquer um não. Eu acho que ele \\
\hline 22 & tem que realmente sentir emoção, sentir prazer. Acredito que não é fácil, porque \\
\hline 23 & dependendo, talvez, se você tentar nivelar o perfil de uma classe dependendo da \\
\hline 24 & situação, não é brincadeira. Acho que vai muito mais além, porque a escola necessita \\
\hline 25 & por professores, colocar professores na escola, no campo, no espaço onde ele vai \\
\hline 26 & trabalhar, mas antes de ensinar tem o saber prévio. Às vezes uma comunidade tá \\
\hline 27 & trabalhando, quais são os problemas, os anseios, as particularidades, por isso que eu \\
\hline 28 & falo que é difícil num grupo você tentar, no aspecto macro, atingir o micro. Cada \\
\hline 29 & elemento daquele ali, é, a questão dá, acho, que é a saúde na sala de aula, que eu falo \\
\hline 30 & da qualidade do ensino, que eles tanto primam, não é isso? Eu aprendi com o tempo, na \\
\hline 31 & minha vida, antes mesmo de iniciar a faculdade, que às vezes a gente precisa saber \\
\hline 32 & valorizar os heróis locais ao invés de certos elementos da história considerados heróis, \\
\hline 33 & que talvez cabe ao tempo provar se é ou não. Mas existem verdadeiros heróis locais. \\
\hline 34 & Eu falo que certos elementos da comunidade, educadores, se o professor, ou aqueles \\
\hline 35 & educadores natos, que não entram na sala de aula, mas eles sabem educar, promover a \\
\hline 36 & educação, são esses os verdadeiros heróis. É isso que a sociedade, a comunidade, tem \\
\hline 37 & que tentar construir. Não é fácil, é difícil, mas acho que vai é disso. \\
\hline
\end{tabular}

O estudante enfatiza sua perspectiva individual (linha 1) e passa a descrever vários aspectos que em sua opinião são importantes para ser professor, sendo que o primeiro aspecto diz respeito à valorização da pessoa como ser humano (linha 2), o que seria muito mais do que instruir. Afirma (sem muita certeza, pelo uso do verbo achar) que educar "é muito mais que isso" (linha 3), mas não completa seu raciocínio, não defende sua perspectiva. O segundo aspecto apontado por ele é "o salário" (linha 4). O terceiro aspecto diz respeito à importância da figura do educador, que não sabe se foi aprendida em casa ou em outro lugar qualquer. Ele menciona os ex-professores para mostrar a influência que tiveram na sua vida (linhas 10,11, 12 e 13). O estudante faz uma generalização quando se refere ao domínio de conteúdo por parte do professor dizendo que esse domínio está relacionado com o aspecto emocional: "o coração é que é o transmissor" (linha 14). Ele 
mostra como se apropriou do que esses professores ensinaram e como utiliza isso na sua prática de extensionista rural (linhas 16,17, 18 e 19). Além disso, ele aponta o que é ser professor quando diz que este tem que "gostar do que faz" (linha 21) e quando expressa, sem muita certeza, "eu acho que ele tem que realmente sentir emoção, sentir prazer” (linha 22). Nesse trecho, volta a responder à pergunta, parecendo se remeter ao "professor" genericamente, não mais relacionando-se à sua atividade de extensionista.

Daí em diante, para expor a dificuldade da atividade de extensionista rural, traz expressões como "nivelar o perfil de uma classe" (linha 23), "escola" (linha 24), "saber prévio" (linha 26), "sala de aula" (linha 29), "qualidade de ensino" (linha 30), que provavelmente dialogam com conteúdos da Educação e que possivelmente foram usadas no curso de licenciatura, misturando-as a outras expressões que remetem, provavelmente, à sua atividade de extensionista rural, como, por exemplo, "campo" (linha 25), "comunidade" (26), "espaço onde vai trabalhar" (linhas 25 e 26). Ele reafirma sua perspectiva individual construída sobre sua experiência profissional quando declara: "eu aprendi com o tempo na minha vida, antes mesmo de iniciar a faculdade” (linhas 30 e 31). Além disso, afirma o que é ser professor na sua concepção e associa a imagem deste à figura de um herói (linhas 34, 35 e 36). Percebemos, aí, a representação do professor como herói (Campos, 2008) e que esse caráter pode ser algo pré-determinado, na medida em que o professor (herói) pode ser um educador nato. Ao mesmo tempo, contraditoriamente, ele considera que seja possível a construção de um tal professor pela comunidade.

\section{Pergunta 10: O que é ser professor?}

\begin{tabular}{|c|l|}
\hline 1 & Eu acho que ser professor é saber e ter prazer em ensinar, independente da situação \\
\hline 2 & que ele tá. Acho que é um ser humano também, que tem suas fraquezas, mas é o que a \\
\hline 3 & gente precisa. Ser professor é isso, é coração, gostar do que faz, se não é ser valorizado, \\
\hline 4 & também, em todos os aspectos. Às vezes uma pessoa que está com certas frustrações, eu \\
\hline 5 & noto, a gente percebe isso, então você tem que, às vezes, eu noto, assim, pois tem dia que \\
\hline 6 & eu vou trabalhar, dar um curso, montar, e é difícil, porque você trabalha com pessoas \\
\hline 7 & com diferentes graus de estudo, às vezes pra aplicar um curso numa área técnica, e tem \\
\hline 8 & dia você fica assim, nossa, meu, isso vai dar tudo errado, não, calma. Ás vezes eu chego \\
\hline 9 & e penso não vou pra eles porque eu não tô bem não, senão eles vão ficar preocupados. \\
\hline 10 & Aí eu respiro fundo, começo a falar, tento ficar calmo. Quando eu assusto, tem certos \\
\hline 11 & assuntos que eu tenho, que eu trato, que até fico meio arrepiado, não sei vai dando \\
\hline 12 & aquela emoção, uma coisa boa. Eu saio de lá assim, esgotado, cansado. Mas eu falo \\
\hline 13 & assim, oh! Caramba! A cabecinha no travesseiro agora fica tranquila, que pelo menos \\
\hline 14 & a minha parte eu fiz. Eu não sei até onde isso tá dando. E acho que é isso que é o \\
\hline 15 & “tchan” dele, do professor. Sabe? É mostrar pro aluno, às vezes, que não é decorar \\
\hline 16 & aquele conteúdo, é tentar entender, pelo menos até ensinar isso. A essência daquilo, \\
\hline
\end{tabular}




\begin{tabular}{|l|l|}
\hline 17 & mostrar, assim, a importância. Muitas vezes, meu caso, me colocando não talvez como \\
\hline 18 & educador, um educador em formação, fazendo analogias daquilo que tem dentro dela, \\
\hline 19 & se apropriando do saber prévio da pessoa, é difícil até mensurar esse resultado, mas \\
\hline 20 & quando você adquire a confiança da pessoa, eu acho que isso é o maior termômetro \\
\hline 21 & que pode provar essa relação ensino-aprendizagem, dessa interação professor-aluno, \\
\hline 22 & aluno-professor. É quando as barreiras, acho que se rompem e você não sabe distinguir \\
\hline 23 & quem é professor, quem é aluno. Naquele momento, o que importa é a construção \\
\hline 24 & coletiva do conhecimento, é o que eles chamam de sabedoria, pelo menos eu tento \\
\hline 25 & entender isso. \\
\hline
\end{tabular}

Quando o estudante afirma que ser professor "é saber e ter prazer em ensinar, independente da situação que ele tá" (linhas 1 e 2), é possível perceber a dimensão do heroísmo associada à figura do professor, o que o entrevistado já insinuava no final do enunciado anterior. Em seguida, faz generalizações a respeito da função docente com base no seu cotidiano como extensionista rural (linhas 4, 5, 6, 7, 8, 9 e 12) para chamar atenção para a dificuldade da relação pedagógica e para o heroísmo dessa atividade: "Eu saio de lá assim, esgotado, cansado" (linha 12). Ele assemelha, mais uma vez, sua experiência profissional à atividade de um professor, quando conclui: "E acho que é isso que é o 'tchan' dele, do professor" (linha 14).

Ao final, a partir de sua experiência profissional ("meu caso", linha 17), esboça sua concepção da relação professor-aluno: "É quando as barreiras, acho que se rompem, e você não sabe distinguir quem é professor, quem é aluno. $\mathrm{Na}$ quele momento o que importa é a construção coletiva do conhecimento, é o que eles chamam de sabedoria" (linhas 22, 23, 24 e 25). Assim, ele mistura expressões de cunho pedagógico à descrição de sua experiência como extensionista rural, que seria semelhante, no discurso, à experiência de um professor.

\section{CONSIDERACְÕES FINAIS}

A partir dos primeiros enunciados, podemos inferir que o estudante justifica seu ingresso no curso a distância de licenciatura em Ciências Biológicas pela possibilidade de manter sua atual atividade profissional e pela convergência entre o conteúdo do curso e o de sua profissão, deixando claro, no entanto, que se tratou apenas de uma alternativa viável diante do seu real interesse, que seria um curso na área de Ciências Agrárias. De um modo geral, a perspectiva individual e enunciados marcados por sua identidade profissional de extensionista rural foram preponderantes em todas as justificativas de sua opção pela modalidade de ensino a distância e pelo curso de licenciatura, inclusive quando ele considera que está se beneficiando das habilidades didáticas aprendidas no curso em seu desempenho profissional. Foi possível perceber, também, que essa opção não correspondia aos seus reais anseios profissionais, adquirindo o sentido de prêmio de consolação. 
O estudante parece reconhecer o estágio como atividade marcante e positiva no seu processo de formação e como principal elo com a realidade escolar. $\mathrm{O}$ fato de ele ter tomado a parte (o estágio presencial) pelo todo (o processo formativo) foi significativo, pois essa operação silencia todo o restante do curso realizado a distância, como, por exemplo, as disciplinas, a relação das disciplinas com o seu processo formativo, a interação com os professores e com os outros estudantes. Essa composição nos leva a supor que as atividades a distância tenham tido pouco impacto sobre sua formação, até porque as interações pelas TDIC foram explicitamente consideradas por ele como pouco intensas.

Ele critica o conteúdo do curso, que considera superficial. Embora essa crítica possa apontar para a falta de qualidade do curso, também é preciso levar em conta que sua avaliação toma como referência a atividade de extensionista rural e não a atividade de um professor de Ciências Biológicas. De qualquer forma, consideramos que esse aspecto do curso possa ter levado a uma fragilização da construção de uma identidade docente e ter contribuído para a preservação de sua identidade de extensionista rural.

Nos últimos enunciados, em que avalia a formação docente e dá significado ao "ser professor", o estudante assemelha sua experiência de extensionista rural à atividade de um professor, dialogando com sua experiência profissional e produzindo enunciados híbridos nos quais é possível perceber, ao mesmo tempo, dois acentos, duas perspectivas que misturam palavras retiradas de contextos diferentes.

Concluímos que a construção discursiva da identidade docente do estudante caracteriza-se por hibridismo, o que pode estar relacionado, principalmente, ao seu apego à identidade profissional de extensionista rural, manifestado de várias formas durante a entrevista. A mistura de discursos que produz sua identidade docente fica evidente quando ele se refere ao curso de licenciatura como formação continuada. Nesse ponto, ele não deixa dúvida de que sua referência de formação é aquela relativa à sua atividade profissional técnica e a licenciatura vem a somar, ou se misturar, à sua identidade anterior.

Nesse sentido, julgamos que estudos como este, que buscam ouvir o estudante para compreender o fenômeno formativo, sempre complexo, são capazes de mostrar como representações e crenças trazidas por eles concorrem com discursos produzidos no curso para forjar a identidade profissional. Assim, julgamos importante implicação deste estudo propor que representações de professor já levantadas na literatura (por exemplo, CAMPOS, 2008, LEITE et al., 2010, COSTA et al., 2011) sejam objeto de discussão nos cursos de licenciatura presenciais ou a distância. Outros fatores levantados nesta análise também devem ser contemplados, como a opção do estudante pelo curso, o papel das relações intersubjetivas e a avaliação dos conteúdos.

Entretanto, não é possível ignorar que as condições socioculturais que circundam o fenômeno em pauta também estão obviamente implicados na preservação da identidade profissional original do entrevistado. Seu compromisso com sua atividade profissional atual, ainda que seja um cargo técnico, justifica-se 
pela estabilidade econômica e social que representa um emprego público no cenário social brasileiro. A profissão docente, restrita ao ensino básico, ocupa o lugar oposto na sociedade, sem prestígio social, sem remuneração adequada e sem atenção suficiente dos governantes. Em um cenário como este, não é difícil compreender por que o estudante tenha hesitado em abandonar sua identidade profissional. O curso de licenciatura, no contexto de desvalorização e precarização do trabalho docente em nosso país, não conseguiu alterar o seu percurso, comum a tantos outros licenciandos, profissionais de outras áreas, que ainda não possuem cursos de nível superior e buscam nesses cursos apenas uma certificação para conquistar níveis mais altos na profissão original.

Este estudo lança luz sobre a problemática da licenciatura vivenciada hoje no país, especificamente sobre a EaD, na formação docente. Por um lado, o perfil do estudante investigado pode ser representativo de alunos de cursos de licenciatura a distância que têm, em geral, idade superior à faixa etária de jovens entre 18 e 24 anos, e trajetória de vida e experiências profissionais estáveis e que, justamente por isso, já possuem identidades profissionais consolidadas, mesmo que associadas a cursos técnicos ou outras ocupações de nível médio. Foi possível mostrar como esse perfil poderá se mesclar à construção de uma identidade docente. Por outro lado, também foi possível levantar possíveis limitações da EaD no contexto do curso investigado.

\section{NOTAS}

${ }^{1}$ Em 2006, 72,3\% da oferta de EaD se concentrava na área de Educação, sendo 76,4\% das matrículas nos cursos de Pedagogia e Normal Superior oferecidos por instituições privadas.

${ }^{2}$ Essa instituição, cuja sede está situada no Estado de Minas Gerais, implantou, em 2000, o Programa de Educação a Distância, que compreendia cursos de especialização lato sensu. A partir de 2002, passou a oferecer cursos de licenciatura a distância em Ciências Biológicas, Geografia, História, Letras, Matemática e Química. A oferta de cursos de graduação a distância passou por um rápido crescimento desde sua implantação, inciando com um curso de Pedagogia até chegar a 15 cursos, abrangendo áreas das Ciências Exatas e Humanas. Funcionando inicialmente com dois polos de apoio presencial, atualmente conta com 39 polos no total, situados em oito estados brasileiros, distribuídos por todas as regiões do país, sendo a região sudeste a de maior concentração. Em 2007, foi implantado o polo de apoio presencial na cidade de Barbacena (MG), cuja população é de 121.571 habitantes (IBGE, 2010). Todo esse crescimento da EaD levou a instituição a descontinuar o curso de licenciatura em Ciências Biológicas na modalidade presencial em 2006.

${ }^{3} \mathrm{O}$ principal objetivo dessa atividade é desenvolver processos educativos que fomentem a construção da consciência crítica das famílias rurais para compreensão de sua realidade. Para tal, é preciso apropriar-se dos conhecimentos necessários para atuação nas ações individuais e de organização coletiva, visando a uma reflexão conjunta e observação compartilhada, com o intuito de materializar a melhoria da qualidade de vida das famílias.

Fonte http://www.emater.mg.gov.br/portal.cgi?flagweb=site_tpl_paginas_internas\&id=8 


\section{REFERÊNCIAS}

ANDRÉ, M. Estudos de caso revelam efeitos sócio-pedagógicos de um programa de formação de professores. Revista Lusófona de Educação, Lisboa, Portugal, n. 6, p. 93-115, 2005.

BAKHTIN, M. The dialogic imagination. Edited by Michael Holquist. Austin: University of Texas Press, 1981.

BAKHTIN, M. Marxismo e filosofia da linguagem. 7. ed. São Paulo: Hucitec., 1995.

BAKHTIN, M. Estética da criação verbal. São Paulo: Martins Fontes, 1997.

BARRETO, R. G. Tecnologia e Educação: trabalho e formação docente. Educação \& Sociedade. Campinas, vol. 25, n. 89, p. 1181-1201, Set./Dez. 2004.

BARRETO, R. G. As tecnologias na política nacional de formação de professores a distância: entre a expansão e a redução. Educacão\& Sociedade. Campinas, vol. 29, n. 104 - Especial, p. 919-937, out., 2008.

BRASIL, Ministério da Educação. Instituto Nacional de Pesquisas Educacionais Anísio Teixeira. Censo da Educação Superior 2010: divulgação dos principais resultados do Censo da Educação Superior/ outubro de 2011. Disponível em < portalmec.gov.br/índex.php?option=docman\&task>. Acesso: 17 de junho de 2012.

BRASIL, Ministério da Educação. Instituto Nacional de Pesquisas Educacionais Anísio Teixeira. Censo da Educação Superior 2011: resumo técnico. Brasília: Instituto Nacional de Estudo e Pesquisas Educacionais Anísio Teixeira, 2013. Disponível em <http://download.inep.gov.br/educacao_ superior/censo_superior/resumo_tecnico/resumo_tecnico_censo_educacao_superior_2011. pdf>. Acesso: janeiro de 2014.

CAMPOS, J. R. "Era um sonbo de criança": a representação social da docência para os professores do município de Queimado-PB. Dissertação (Mestrado em Educação) - Universidade Federal do Rio Grande do Norte, Natal, 2008.

COSTA, M. L. R.; BEJA, A. C. e REZENDE, F. Traços identitários de professores de Física representados por imagens. In: VIII ENCONTRO NACIONAL DE PESQUISA EM EDUCAÇÃO E CIÊNCIAS, 8., 2011. Campinas, SP. Anais... Campinas, SP: ENPEC, 2011.

FERRAZ, G. Perspectivas de professores de fisica sobre as politicas curriculares nacionais para o ensino médio. Dissertação (Mestrado) - Programa de Pós- Graduação em Educação em Ciências e Saúde Universidade Federal do Rio de Janeiro, Rio de Janeiro, 2012.

FREITAS, L. F. A identidade cultural na interface com os estudos enunciativos e discursivos. SEMINÁRIO INTERNACIONAL DE TEXTO, ENUNCIAÇÃO E DISCURSO, 2010. Porto Alegre, RS. Anais... Porto Alegre: PUCRS, 2010.

GIOLO, J. A educação a distância e a formação de professores. Educação $\mho$ Sociedade. Campinas, vol. 29 , n. 105 , p. 1211-1234. 2008.

HALL, S. Quem precisa da identidade? In: T. T. da Silva (Org.) Identidade e diferença: a perspectiva dos estudos culturais. 10 ed. Petrópolis: Vozes, 2011.

LAPA, Andrea Brandão; BELLONI, Maria Luiza. Educação a distância como mídia-educação. Perspectiva, Florianópolis, v. 30, n. 1, p. 175-196, 2012.

LEITE, M. C. L.; HYPOLITO A. M e LOGUERCIO R. Q. Imagens, docência e identidade. Cadernos de Educação, Pelotas, v. 36, p. 319 - 335, 2010.

NÓVOA, A. Vida de professores. 2 ed. Porto: Porto Editora, 2007.

SEGENREICH, S. C. D. ProUni e UAB como estratégia de EAD na expansão do Ensino Superior. Pro-Posições, Campinas, v.20, n.2 (59), p.205-222, maio/ago, 2009.

SILVA, M. Cibercultura e educação: a comunicação na sala de aula presencial e online. Revista FAMECOS: Mídia, Cultura e Tecnologia, Porto Alegre, v. 1, n. 37, 2008.

SILVA, T. T. da. A produção social da identidade e da diferença. In: T. T. da Silva (Org.) Identidade e Diferença: a perspectiva dos estudos culturais. 10 ed. Petrópolis, RJ: Vozes, 2011.

SILVA JÚNIOR, J. R. Reformas do estado e da sociedade e as políticas públicas para a formação de professores a distância: implicações políticas e teóricas. Revista Brasileira de Educação, São Paulo, n. 24, p. 78-94, 2003. 
Construção da identidade docente de um estudante de 1icenciatura em Ciências Biológicas em curso a distância: um caso de hibridismo

VENEU, A. A. Perspectivas de professores de física do ensino médio sobre as relações entre o ensino de física e o mercado de trabalho: uma análise Bakhtiniana. Dissertação (mestrado) - Programa de Pós-Graduação em Educação em Ciências e Saúde - Universidade Federal do Rio de Janeiro. Rio de Janeiro, 2012. ZUIN, A. A. S. Educação a distância ou educação distante? O programa Universidade Aberta do Brasil, o tutor e o professor virtual. Educação\& Sociedade. Campinas, vol. 27, n. 96 - Especial p. 935-954, 2006.

ZUIN, A. Antônio S. O Plano Nacional de Educação e as tecnologias da informação e comunicação. Educaçãod Sociedade. Campinas, v. 31, n. 112, p. 961-980, 2010.

Data do Recebimento: 08/07/2013

Data da Aprovação: 24/01/2014

Data da Versão Final: 31/01/2014 